\title{
Analytical Performance of an Inductively Coupled Plasma Optical Emission Spectrometry with Dual View Configuration
}

\author{
Júlio C. J. Silva, Nivaldo Baccan and Joaquim A. Nóbrega
}

\author{
2003, vol. 14, No 2, 210-315.
}

In the Table 2 of the page 311, the correct values of IP and $\mathrm{EP}$ to $\mathrm{Ba}$ II $(455.4 \mathrm{~nm}), \mathrm{Al}$ I $(308.2 \mathrm{~nm}), \mathrm{Ba}$ II $(233.5$ nm), Mn II (260.6 nm), Mn II (257.6 nm), Mo II (203.8 nm), Mo II $(202.0 \mathrm{~nm})$ are 5.21 and $2.72 \mathrm{eV}, 5.99$ and $4.02 \mathrm{eV}$,
5.21 and 6.0, 7.44 and 4.75, 7.44 and 4.81, 7.1 and 6.08, 7.1 and 6.13 , respectively.

In the Table 2 of page 311, the correct value of EP to $\mathrm{Mg} \mathrm{I}(285.2 \mathrm{~nm})$ is $4.34 \mathrm{eV}$. 